BULLETIN Bulletin hispanique

HISPANIQUE Université Michel de Montaigne Bordeaux

118-2 | 2016

Varia

\title{
Las arengas de Alfonso VIII en la Estoria de España
}

\section{J. Carlos Iglesias-Zoido}

\section{OpenEdition}

\section{Journals}

Edición electrónica

URL: http://journals.openedition.org/bulletinhispanique/4460

DOI: 10.4000/bulletinhispanique.4460

ISSN: 1775-3821

Editor

Presses universitaires de Bordeaux

\section{Edición impresa}

Fecha de publicación: 15 diciembre 2016

Paginación: 407-430

ISBN: 979-10-300-0125-9

ISSN: 0007-4640

Referencia electrónica

J. Carlos Iglesias-Zoido, "Las arengas de Alfonso VIII en la Estoria de España », Bulletin hispanique [En línea], 118-2 | 2016, Publicado el 15 diciembre 2019, consultado el 27 diciembre 2019. URL : http:// journals.openedition.org/bulletinhispanique/4460; DOI : 10.4000/bulletinhispanique.4460 


\title{
Las arengas de Alfonso VIII en la Estoria de España
}

\author{
J. Carlos Iglesias-Zoido \\ Universidad de Extremadura
}

Cet article vise à expliquer l'origine, les modèles et la fonction rhétorique des trois harangues militaires prononcées par le roi Alphonse VIII dans le chapitre 1013 de l'Estoria de España d'Alphonse X.

Mots-clés : harangues, rhétorique, historiographie, Estoria de España, Moyen Âge, Pré-humanisme.

El presente trabajo tiene como objetivo explicar el origen, los modelos y la función retórica de las tres arengas militares pronunciadas por el rey Alfonso VIII en el capítulo 1013 de la Estoria de España alfonsí.

Palabras claves: arengas, retórica, historiografía, Estoria de España, Edad Media, Prehumanismo.

This paper aims to explain the origin, the models and the rhetorical function of the three battle speeches pronounced by King Alfonso VIII in the chapter 1013 of Alfonso X's Estoria de España.

Keywords: harangues, rhetoric, historiography, Estoria de España, Middle Ages, Prehumanism.

1. El presente trabajo tiene como objetivo explicar el origen, los modelos y la función retórica de las arengas pronunciadas por el rey Alfonso VIII en el capítulo 1013 de la Estoria de España alfonsí ${ }^{1}$. Estos discursos, que forman

1. Este trabajo se enmarca en el Proyecto de Investigación FFI2015-64765-P y en el Grupo de Investigación "Arenga» (HUM-023) de la UEX. Sobre el tema de las arengas militares y su función en la historiografía desde la Antigüedad hasta el Renacimiento, cf. Iglesias-Zoido (ed.) (2008) con amplia bibliografía para una visión de conjunto. 
parte de un episodio toledano en el que se relatan los acontecimientos que precedieron a la Batalla de las Navas de Tolosa (1212), están ausentes de todas las fuentes previas dedicadas a la batalla, tanto latinas como castellanas, por lo que han llamado poderosamente la atención de los medievalistas ${ }^{2}$. Los autores que han estudiado estas arengas coinciden en señalar que son fruto de una interpolación, inciden en el análisis de su contenido ideológico e intentan fechar el momento en el que pudieron ser incorporadas a la Estoria de España ${ }^{3}$. Sin embargo, los historiadores en ningún momento se plantean la causa por la que estos discursos fueron insertados en la crónica castellana ni explican tampoco sus llamativas características formales y retóricas. Nuestro estudio aporta una explicación basada en un análisis del influjo de la tradición clásica de cuño alejandrino en la elaboración del episodio de la reunión de las tropas cristianas en Toledo en su conjunto, donde también se percibe un nuevo tipo de interacción entre retórica e historiografía. A la luz de nuestra interpretación, creemos que es posible explicar por primera vez tanto el origen como la forma retórica y la función desempeñadas por estas arengas historiográficas.

2. Para entender la significación de las arengas pronunciadas por Alfonso VIII en la Estoria de España hay que partir de la fuente cristiana más importante para conocer lo sucedido en la batalla de las Navas de Tolosa, escrita por un testigo privilegiado de los hechos. Nos referimos a la Historia de rebus Hispaniae de Rodrigo Jiménez de Rada, arzobispo de Toledo (1170-1247) . El relato de la batalla de las Navas de Tolosa, a la que el arzobispo dedica once de los quince capítulos de los que consta el libro VIII de su historia, fue decisivo para la mayor parte de los historiadores posteriores, que consideraron que esta narración era el punto de partida fundamental para elaborar sus propios relatos de esta batalla ${ }^{5}$. En este texto historiográfico hay tres datos relevantes para nuestro estudio. En primer lugar, la conciencia que tenía el arzobispo de describir unos hechos decisivos para la historia castellana ${ }^{6}$. A partir de sus

2. Sobre las fuentes y las características concretas de la batalla de las Navas cf. Alvira Cabrer (2000) y (2012) y, sobre todo, el trabajo de García Fitz (2005), reeditado en 2012 (Edición del VIII Centenario), obra de referencia para conocer todos los aspectos de esta batalla.

3. Seguimos el texto de la Primera Crónica General editado por Menéndez Pidal (1973), revisado en su tercera edición por D. Catalán. Sobre la obra y el proceso de composición del escriptorio alfonsí, cf., sobre todo, los trabajos de Catalán (1963) y (1997) y de Fernández Ordóñez (1988), (1992) y (ed.) (2000), estos últimos con abundante bibliografía actualizada.

4. Seguimos el texto editado por Fernández Valverde (1987) y la traducción de Fernández Valverde (1989) con una buena introducción sobre la figura del arzobispo. Sobre la labor historiográfica desarrollada por el arzobispo, cf. los estudios publicados en el número monográfico 26 de la revista Cahiers de linguistique et de civilisation hispaniques médiévales, entre los que destacamos el clarificador estudio de Arizaleta (2003) con respecto a la presentación de Alfonso VIII como figura real paradigmática en la obra del arzobispo. Al respecto, cf. también Rodríguez (2003).

5. Cf. el catálogo de fuentes (desde el XIII hasta el XVI) que ofrece Alvira Cabrer (2010: 1745 yss.).

6. Cf. sobre todo los capítulos X («Sobre la victoria de los cristianos y el descalabro de los sarracenos») y XI («Sobre las hazañas de los combatientes»). 
palabras queda claro que la batalla de las Navas de Tolosa fue el momento cumbre de la cruzada que tanto el rey Alfonso VIII de Castilla como el Papa Inocencio III habían convocado para luchar contra los almohades. El objetivo era derrotar a unas huestes musulmanas que, como consecuencia de su victoria sobre los cristianos en la Batalla de Alarcos de 1195, habían recuperado la iniciativa y amenazaban a la propia ciudad de Toledo y al Valle del Tajo en su conjunto. Pero la trascendencia de la victoria del rey Alfonso fue de tal calibre que acabó facilitando la conquista definitiva de los territorios del sur de la Península. En segundo lugar, la obra de Jiménez de Rada se destaca por la importancia otorgada al relato de los hechos previos a la batalla, entre los que ocupa un lugar decisivo la reunión en la ciudad de Toledo de las tropas cristianas que acabaron tomando parte en la lucha. Jiménez de Rada, con la intención de destacar el papel jugado por el liderazgo de Alfonso VIII, se detiene a lo largo de los cuatro primeros capítulos del libro VIII (un tercio del total dedicado a la batalla en su conjunto) en la narración de los hechos allí acaecidos tras la llegada a la ciudad castellana de contingentes de muy variada procedencia: castellanos, espańoles y ultramontanos. Una narración que, curiosamente, ocupa más espacio que el dedicado a su salida hacia el frente, a la toma de Malagón y, en definitiva, al relato concreto del enfrentamiento entre moros y cristianos en tierras de Jaén. En tercer lugar, hay que señalar que el arzobispo no incluyó discursos que, a la manera de la historiografía grecolatina, aportasen datos y perspectivas complementarias del enfrentamiento 7 . Por lo tanto, el principal testigo de los hechos no ha legado a la posteridad información sobre los discursos exhortativos que pudiera haber pronunciado el rey Alfonso VIII ni en la reunión de las tropas cristianas en Toledo ni tan siquiera en el momento de la batalla ${ }^{8}$. Las únicas palabras del rey en estilo directo que aparecen en este suceso se corresponden con un breve diálogo con el propio arzobispo de Toledo en mitad de la lucha9. Un comportamiento historiográfico que, por otro lado, se observa en la mayor parte de las crónicas hispanas de la primera mitad del siglo XIII en las que los discursos apenas tienen importancia para explicar el desarrollo de los acontecimientos ${ }^{10}$. Y, de hecho, otras obras latinas contemporáneas elaboradas en el marco castellano, como el Chronicon Mundi de Lucas de Tuy, siguen este mismo proceder a la hora de relatar lo sucedido en esta batalla ${ }^{11}$.

7. Cf. Alvira Cabrer (2000: 390): «Para Rodrigo de Toledo, por tanto, la arenga no es un hecho destacado dentro del ritual de la batalla».

8. De hecho, Jiménez de Rada sólo menciona los discursos de ánimo pronunciados por los obispos en el campamento cristiano antes de la batalla (Libro VIII, cap. VIII): «el arzobispo de Toledo y los demás obispos predicaban palabras de ánimo y de indulgencia con gran unción por cada uno de los campamentos de las ciudades y los príncipes» (Fernández Valverde 1989: 319).

9. Cf. Libro VIII, cap. X: «Arzobispo, muramos aquí. Pues no es deshonra una muerte tal en tales circunstancias» (Fernández Valverde 1989: 322).

10. Cf. Linehan (1993) para el contexto general de esta historiografía hispana.

11. Cf. Chronicon mundi, IV, 89-90, en Falque (2003 : 329-330). El tudense destaca la excepcionalidad del enfrentamiento de las Navas al afirmar que in Yspania simile bellum nunquam fuit (Falque 2003: 330). Cf. también Alvira Cabrer (2012: 198-207), quien hace un repaso de las 
3. La crítica señala que la obra del arzobispo es la fuente principal seguida en la elaboración de los capítulos 1010 y ss. de la Estoria de España alfonsi' ${ }^{12}$. De hecho, en gran medida se trata de una traducción castellana más o menos fiel del texto latino en la que no hay grandes diferencias con respecto a los datos y al enfoque en lo que atañe a dos de los factores señalados: la trascendencia dada al enfrentamiento y el papel desempeñado por los sucesos previos acaecidos en Toledo. Por ello mismo, y en claro contraste, llama poderosamente la atención el capítulo 1013 de la historia alfonsí, en el que se relatan los antecedentes de la gran batalla y donde los narradores se detienen en la descripción del comportamiento del rey Alfonso VIII. Se trata de un pasaje que tiene como objetivo ensalzar la figura del rey castellano: El capitulo dell avantaia de las virtudes et de la franquez que el noble rey don Alffonso avie sobre los otros ${ }^{13}$. Es cierto que los redactores ponen de manifiesto constantemente que la fuente principal empleada originalmente en el scriptorium de Alfonso X a la hora de relatar estos hechos decisivos, tal y como se indica expresamente en el texto, había sido la crónica escrita por Jiménez de Rada ${ }^{14}$. Sin embargo, mientras que en la crónica del arzobispo sólo se exponen hechos, en la versión alfonsí encontramos, en cambio, al rey Alfonso VIII pronunciando una serie de discursos que toman la forma de arengas en estilo directo y que desempeñan un papel esencial en el desenlace de los acontecimientos ${ }^{15}$. Por medio de ellas, los cronistas presentan al rey castellano exhortando a la lucha a los diferentes contingentes que conforman el bando cristiano con unos discursos que ocupan la mayor parte del capítulo en cuestión. Así, en primer lugar, Alfonso se dirige a sus «naturales», los castellanos, en el contexto de lo que es denominado como unas «cortes» («et fizo sus cortes con ellos et dixoles...») por parte del narrador:

Et pora guisar esto ell muy noble rey don Alffonsso, diremos del su muy complido seso que fizo: fizo partes destas yentes, et ayunto luego en la primera los fijosdalgo et los otros omnes de armas sus naturales, et fizo sus cortes con ellos et dixoles: «Amigos, entre todas estas yentes que aqui veedes, vos sodes mios naturales et sodes fijos dalgo, et todos avedes derecho en bien. Et bien creet que, en el regno, el que mas sabe de sus fijosdalgo -dond vienen cada unos, et quales son en sus costumbres et quales

muy escasas veces en las que aparecen las palabras del Rey Alfonso VIII en las distintas crónicas castellanas del siglo XIII. Para estos autores, «los discursos vuelven a importar menos que los hechos», Alvira Cabrer (2012: 198).

12. Cf. PCGE vol II (Menéndez Pidal 1977: 692 ss.)

13. Cf. el título latino del cap. IIII del libro VIII de la Historia de Rada: «De prerogativa virtutum et largitatis nobilis Aldefonsi» (Fernández Valverde 1987: 262-264).

14. Cf. Menéndez Pidal (1977: 692, 11. 30-31): « ...mas dize ell arzobispo -que era y en todos estos fechos- que maguer que esto assi era...»; (1977: 694, 1l. 3-4): «et dize el arzobispo don Rodrigo que fallaron...».

15. Cf. Alvira Cabrer (2000: 400): «Leyendo este texto puede comprobarse que la Primera Crónica General es la única crónica que hace de la arenga una parte fundamental del recuerdo de Las Navas. De hecho, el autor concede a los supuestos discursos de Alfonso VIII mucha más importancia, tanto en dimensiones como en ideas, que a otros episodios de la campaña». Cf. Bliese (1989) y (1991), quien analiza los tópicos argumentativos empleados en las arengas insertadas en crónicas europeas hasta mediados del siglo XIII. Cf. también García Fitz (2008). 
enhardiment de armas, et quales los leales a sennor, et de las otras yentes de los logares del regno quales son los que prez an de meiores omnes, et quales son los que mas et meior guardaron todavia nobleza de fidalguia et los sus derechos- el qui meior lo sabe et meior los connosçe, ell rey es»; et por darles mas vivos coraçones et ençenderlos et assanarlos pora la batalla, dixoles adelant assi: «Catad agora, mios amigos, quales sodes los que avedes mester cavallos et non los tenedes, et quales avedes mester las armas, et quales los pannos, et quales los dineros, et quales las otras cosas que mester sean; venid a mi et demandatme, ca yo complire a todos de todo». Et assi como lo dixo, assi lo cumplio luego a todos; et dioles cavallos, et dioles armas et dioles dineros, et aun dioles cavallerias a los que las non avien et eran pora ellas. Et fizolos a todos tan sus pagados et tan sus amigos, que todos alçaron las manos et dixieron: «sennor, yd por o quisierdes, ca convusco yremos et nunqua vos fallesçremos; et aun, si mester fuere, y queremos morir; mas que mas, que vençremos a los enemigos de la cruç et nuestros, et viuremos».

El rey castellano pone de manifiesto en su discurso, a modo de introducción, que el que mejor conoce las necesidades de sus «fijosdalgo» es el rey (...«el qui meior lo sabe et meior los connosçe, ell rey es.»). Pero, sobre todo, "para darles mas vivos coraçones et ençenderlos et assanarlos pora la batalla», los interpoladores han puesto en boca del rey una exhortación centrada en los beneficios materiales que les deparará la batalla, ofreciéndose a proporcionarles caballos, armas y todos los medios que necesiten («...venid a mi et demandatme, ca yo complire a todos de todo»).

Acto seguido, y sin que medie nada más, se nos informa de que el rey castellano se reunió «otro día» con los contingentes procedentes de Aragón, Portugal, Galicia y Asturias, a las que denomina con el apelativo común de «espannoles»:

Desque los sus naturales ovo el rey don Alffonsso puesto en recabdo desta guisa, apartosse otro dia con los de Aragon et portogaleses et gallegos et asturianos, essos que y vinieron, et dixoles assi el rey don Alffonso: «Amigos, todos nos somos espannoles, et entraronnos los moros la tierra por fuerça et conquirieronnosla, et en poco estidieron los cristianos que a essa sazon eran, que non fueron derraygados eet dechados della; et essos pocos que fincaron de nos en las montannas, tornaron sobre si, et matando ellos de nuestros enemigos et muriendo dellos y, fueron podiendo con los moros, de guisa que los fueron allongando et arredrando de si. Et quando fuerça dellos, como eran muchos ademas, vinie a los nuestros dond nos venimos, llamavanse a ssus ayudas, et vinien unos a otros et ayudavanse, et podian con los moros, ganando siempre tierra dellos, fasta que es la cosa venida a aquello en que vedes que oy esta. Et assaz oyestes todos el mal que a mi fizieron en la batalla de Alarcos; et llamevos por ende a esta otra et vos ayunte aqui, et pero desta guisa: ell rey de Aragon a su postura conmigo porque veno, los otros viniestes aqui otrossi por limpiarvos de vuestros yerros contra Dios: mas pero a qualquier manera que vengades, ruegovos que vos pese mucho del mio mal et del mio crebanto, et de vuestros cristianos; et pues que aqui sodes, que me ayudedes a tomar vengança et enmienda del mal que e tomado yo et la cristiandad. Et catad quales auredes mester cavallos o otras bestias o dineros et viandas o otras cosas, et dezidlo et pedid; ca yo dare et complire de todo a todos». Las compannas, quando oyeron estas razones tan buenas, et estos complimientos que el rey don Alffonsso dizie, gradesçierongelo todos et alçaron las manos et prometieronle aquello mismo que sus castellanos: que fuesse por o quisiesse, ca ellos con ell yrien, et o morrien o vençrien con el. 
En esta segunda ocasión, el discurso puesto en boca del rey sobre todo incide en recordar el mal causado al conjunto de los españoles por las sucesivas invasiones moras, que llegaron a relegar a los cristianos a unas montańas desde las que se ha emprendido la reconquista del territorio hispano, destacando la oportunidad de vengar el mal recibido.

Y, en tercer lugar, el rey es representado en estilo indirecto dirigiéndose a los extranjeros (las "yentes ultramontanas»), grupo conformado por franceses, italianos y alemanes, a los que recuerda la cruzada cristiana que les ha traído hasta tierras de Castilla y la posibilidad de enmendar el daño causado por los musulmanes:

Empos esto, ovo otrossi el rey don Alffonsso su fabla con las yentes ultramontanas, que eran los françeses et los de Leon de sobrel Rodano, et los otros de allent esse ryo Rodano, et los de Italia, los de Lombardia, los de Alemanna, et predicoles en razon de la eglesia de Cristo et de la cristiandad, diziendoles como en la cristiandad et en la eglesia todos eramos unos, et de como ell su danno alcançaba a todos: que otrossi la su emienda et la su vengança onrra et pro serie de toda la cristiandad et de la eglesia; et que aquellos que mester oviessen cavallos et armas et dineros et viandas, que lo dixiessen et demandasen, ca el complirie todo. Ellos respondieronle como avedes oydo quel respondieran los otros: que yrien con ell o fuesse, et o morrien o vençrien con ell.

Es muy interesante el hecho de que, en los tres casos, los narradores ponen de manifiesto que cada uno de los auditorios respondió de manera unánime poniéndose en disposición del rey y declarando que le seguirían hasta la muerte. Así hacen los castellanos («sennor, yd por o quisierdes, ca convusco yremos et nunqua vos fallesçremos; et aun, si mester fuere, y queremos morir»), los espańoles («alçaron las manos et prometieronle aquello mismo que sus castellanos: que fuesse por o quisiesse, ca ellos con ell yrien, et o morrien o vençrien con el») y los ultramontanos («Ellos respondieronle como avedes oydo quel respondieran los otros: que yrien con ell o fuesse, et o morrien o vençrien con ell»). En cierto modo, la insistencia de los narradores en resaltar la similitud de la respuesta hace que el lector no pueda evitar la sensación de estar ante un solo discurso, con partes dirigidas a tres diferentes sectores del público y que recibe una misma y unánime respuesta.

4. El contraste de este episodio con respecto a lo que relatan los crónicas latinas utilizadas como fuente es muy llamativo, ya que, como hemos señalado, en las crónicas más próximas a la batalla no hay ninguna referencia a que se pronunciasen arengas como las ahora insertadas. Ante estas diferencias, la crítica considera que estamos ante un pasaje interpolado que, en una segunda redacción más tardía, habría completado la información procedente de la obra de Jiménez de Rada por medio de la inclusión de los discursos. En esos mismos trabajos, ante la falta de referentes previos sobre su pronunciación, se destaca el hecho de que estas arengas han sido inventadas sin más. Para García Fitz, el conjunto de ideas desarrollado en las tres arengas, desde lo más local a lo más universal, sería el medio que emplearon los redactores de la crónica (o de la interpolación) para mostrar a los lectores «una mezcla de razones históricas, 
políticas, jurídicas y religiosas que forman las distintas construcciones teóricas que habitualmente conocemos bajo los apelativos de guerra justa, guerra santa, cruzada o reconquista» ${ }^{16}$. Para Alvira Cabrer, "lo más probable es que este episodio ocurrido en Toledo no fuera real. Las fuentes coetáneas y más fiables nada dicen de ello» ${ }^{17}$. Nos encontramos, por lo tanto, ante una cuestión que, a pesar de su importancia, ha quedado sin responder por los medievalistas, que optan por un análisis de la ideología subyacente a esas intervenciones y su adecuación a las claves políticas del momento ${ }^{18}$. $\mathrm{O}$ que, en todo caso, se plantean el momento en el que habrían sido interpolados estos discursos en el texto castellano que seguía lo relatado por la crónica de Jiménez de Rada ${ }^{19}$. Cuestión en la que tampoco hay unanimidad, ya que se barajan unas fechas que van desde el último tercio del siglo XIII hasta bien entrado el siglo XIV. Hay autores que consideran que la inclusión de las arengas pudo hacerse en plena época alfonsi $i^{20}$. Otros, como F. Bautista, retrasan la interpolación de las arengas hasta el año 1289, durante la elaboración de la Versión amplificada de la Estoria de España o Versión de Sancho $I V^{21}$. Y, finalmente, hay autores, como Rodríguez Velasco, que retrasan esta fecha hasta el reinado de Alfonso $\mathrm{XI}^{22}$. Estas divergencias se explican por la compleja historia editorial de esta parte de la obra alfonsí23. Y es que la Estoria de España tal y como ha llegado hasta nosotros es el resultado de dos diferentes momentos de elaboración: la Versión primitiva, escrita entre los años 1260 y 1274, y la Versión crítica, que añadió y refundió el material de la versión inicial, terminada hacia 1274, con los añadidos en una segunda redacción que se prolongó desde finales del siglo XIII (en el reinado de Sancho IV) hasta bien entrado el XIV (reinado de Alfonso XI) con el aporte de diferentes materiales históricos y literarios extraídos de otras fuentes, muchas veces con una nueva visión de la narración histórica.

5. Como puede comprobarse, en la bibliografía dedicada a estudiar este episodio no se llega a plantear ni la procedencia ni la causa de la introducción de estas arengas en este pasaje en concreto. Pero lo que parece un callejón sin salida para los historiadores, preocupados básicamente por un tema de fuentes o por el contenido ideológico de los discursos puestos en boca del rey castellano $^{24}$, creemos que puede aclararse atendiendo a un aspecto formal y

16. Cf. García Fitz (2005: 392-394).

17. Cf. Alvira Cabrer (2000: 400).

18. Cf. Alvira Cabrer (2000: 400): «En todo caso, lo relevante no es que sucediera, sino la ideología que subyace bajo los supuestos discursos del rey...».

19. Cf. Alvira Cabrer (2012: 213): «Lo seguro es que estamos ante un texto de origen desconocido que fue interpolado a una traducción castellana del Toledano en, al menos, dos momentos posibles..."

20. Cf. Alvira Cabrer (2012: 213-218), donde se hace una amplia exposición de los factores ideológicos e históricos que podrían fundamentar una u otra hipótesis.

21. Cf. Bautista (2006: 73-75).

22. Cf. Rodríguez Velasco (1993-1994: 57).

23. Cf. Catalán (1997).

24. Cf. Alvira Cabrer (2000: 405-6): «La respuesta es difícil de contestar, pues desconocemos de qué fuente bebió el compilador alfonsí». 
retórico en el que la tradición clásica habría jugado un papel muy destacado. No olvidemos que la novedad de este capítulo se encuentra en la inclusión, a la manera de la historiografía grecorromana, de una serie de discursos en estilo directo que permiten al lector acceder a las palabras del rey Alfonso VIII. Desde este punto de vista, la clave para entender cómo se ha reelaborado este pasaje se encuentra en la relación entre retórica e historiografía y en los diferentes modos en que el legado grecolatino fue interpretado entre los siglos XIII y XIV ${ }^{25}$. De hecho, desde el punto de vista de la tradición clásica, el pasaje, en sí mismo, ofrece un ejemplo de la renovada importancia de la retórica y del discurso como elementos esenciales del relato historiográfico. Veámoslo punto por punto.

6. El punto de partida del texto alfonsí, como ya hemos indicado, es el relato de la reunión de las tropas cristianas que ofrece Jiménez de Rada en su Historia de España (Libro VIII, caps. I-IIII). Se trata de un episodio fundamental para entender la repercusión del futuro enfrentamiento con los almohades: la reunión de todos los contendientes (castellanos, españoles y ultramontanos) en Toledo, que en ese momento era la capital del reino. Todo ello rematado con un capítulo claramente retórico en el que el arzobispo tiene el objetivo de ensalzar las cualidades de Alfonso VIII como rey, que lleva el siguiente encabezamiento: Sobre la excelencia de las virtudes y la generosidad (largitatis) del noble Alfonso (libro VIII, cap. IIII):

Aunque no era fácil de gobernar una muchedumbre tan abigarrada, tan distinta, tan opuesta, ni siquiera para el más paciente, sin embargo el noble rey con su gran corazón todo lo llevaba con tranquilidad, todo con quietud, todo con justicia, de manera que el aburrimiento lo trocaba en virtud, superándolo con alegre semblante; las palabras desmesuradas tornaba en mesura con su mesurada respuesta; la ceñuda charlatanería de la ambición la transformaba en alegre discurso con su generosa mano; con simpática camaradería participaba en las paradas militares, sin que se resintiera un ápice la gravedad del porte real ... de manera que se podía decir de él: posee más virtudes que todos los demás juntos... ${ }^{26}$

Es un pasaje que, además, hay que poner en relación con el relato de la muerte del monarca (1. VIII, cap. XV), en el que Rada destaca las cinco virtudes que caracterizaron a Alfonso VIII: strenuitas, largitas, curialitas, sapientia y modestia ${ }^{27}$. Un aspecto en el que ha incidido A. Arizaleta, quien ha estudiado el claro enfoque encomiástico de este capítulo destinado a ensalzar la figura del rey castellano dentro de las claves del poder regio en el siglo XIII ${ }^{28}$. Sin embargo, desde nuestro punto de vista, teniendo en cuenta el énfasis que, a lo largo de todo el capítulo IIII, Rada ha puesto en destacar una serie de cualidades reales, entre las que se destaca de manera especial la liberalidad (la largitas que aparece claramente separada del resto de las virtudes en el título), defendemos la hipótesis de que el Toledano estaría ensalzando una figura

25. Cf. González Rolán, Saquero, López Fonseca (eds.) (2000).

26. Cf. Fernández Valverde (1989: 311), cursivas nuestras.

27. Cf. Fernández Valverde (1989: 329).

28. Cf. Arizaleta (2003: 169-172). 
real cuyas virtudes hay que entender en clave alejandrina ${ }^{29}$. Un proceder que no sería extraño si tenemos en cuenta que la propia Arizaleta ha puesto de manifiesto que el obispo prestó una especial atención a la figura de Alejandro y a su modelo como monarca ${ }^{30}$. Y que, incluso, habría intentado usar esta figura en otros lugares de la obra como modelo del comportamiento del rey castellano Alfonso VIII ${ }^{31}$. A la vista de estos datos, pensamos que el obispo castellano, al redactar el episodio de los antecedentes de la batalla de las Navas, intenta trazar un paralelo erudito con un episodio de la vida de Alejandro que tiene gran importancia en la tradición medieval del macedonio. Nos referimos a las "cortes» convocadas por Alejandro justo tras la muerte de Filipo, en las que reúne a todos los griegos y exhorta a emprender contra el enemigo persa la lucha que habrá de liberar definitivamente a los griegos. Ocasión en la que el rey macedonio acabó dirigiendo a los participantes un discurso exhortativo de gran importancia para entender la trascendencia de la empresa militar que se iba a acometer.

7. Es muy significativo que este episodio de las «Cortes convocadas por Alejandro", del que no tenemos constancia en las fuentes conservadas de la Vulgata alejandrina difundida durante la Antigüedad, tenga gran peso en toda la tradición medieval de Alejandro ${ }^{32}$. Este episodio no procede realmente de las obras historiográficas dedicadas al macedonio, sino que lo encontramos en una obra griega de la antigüedad tardía con un claro contenido novelístico como es la Vida y hazañas de Alejandro de Macedonia atribuida al Pseudo-Calístenes, en donde Alejandro, tras la muerte de Filipo, se dirige a los macedonios y a los griegos en los siguientes términos (1.25):

Una vez que la ciudad de Pela recobró la normalidad, subió Alejandro sobre el monumento a su padre Filipo y a grandes voces dijo: «iHijos de los peleos y de los macedonios, de los griegos y de los anfictiones, acudid a reuniros conmigo, como camaradas de armas, y confiad en mí, para realizar nuestra expedición contra los bárbaros! ¡Vamos a liberarnos de la esclavitud de los persas, a fin de que no seamos esclavos de los bárbaros, siendo griegos nosotros!» Tras haber pronunciado su discurso, distribuyó Alejandro por todo el país sus decretos reales. Entonces, reuniéndose gentes de todas las regiones, acudieron a Macedonia todos por su propia voluntad, como si hubieran sido convocados por una voz emitida por los dioses, para alistarse en el ejército $^{33}$.

29. Cf. Cary (1956: 209 ss.): «Alexander's secular reputation of Liberality». Sobre la visión medieval de Alejandro y de sus virtudes, cf. los trabajos recientemente editados por GaullierBougassas (2011) desde la perspectiva historiográfica y Zuwiyya (2011) desde una perspectiva literaria, ambos con bibliografía actualizada.

30. Cf. Arizaleta (2003: 164): «El interés del Toledano por el modelo de Monarquía representado por la figura del macedonio - a la cual dedica buena parte de su mal llamado breviario- es sin duda revelador de su concepción del poder regio».

31. Cf. al respecto Arizaleta (2005).

32. Cf. en este sentido la obra fundamental de Cary (1956). En general, sobre la tradición de Alejandro en la Espańa medieval, cf. Zuwiyya (2011: 231-254) para una bibliografía actualizada.

33. Cf. la traducción de García Gual (1977). 
Esta obra griega, a través de traducciones latinas, tuvo una gran difusión durante el medievo ${ }^{34}$. De hecho, podemos comprobar cómo este episodio también desempeña un papel muy importante en la conocidísima traducción latina de Julio Valerio (Res gestae Alexandri Macedonis) ${ }^{35}$. En esta versión latina, Alejandro aparece dirigiéndose a una representación de hombres de Macedonia y de toda Grecia (o Pellae proles et Macedonum vel Atheniensium Corinthique progenies ceterarumque Graeciae gentium nomina) que han acudido a los funerales de Filipo, y a los que dirige una arenga decisiva (cf. el verbo contionatur). Se trata del primer gran discurso de Alejandro, aquel con el que el macedonio exhorta a luchar por la libertad contra el persa (1.25):

\footnotetext{
Vbi igitur iam moti animi hominum illa rerum novitate quietiores visi potuerunt, scandit Alexander paternae statuae suggestum et propter illam adsistens in haec verba contionatur: "o Pellae proles et Macedonum vel Atheniensium Corinthique progenies ceterarumque Graeciae gentium nomina, en tempus est, quisquis Alexandro sese cupiat militare, ut scilicet nunc nomen labori fateatur. In eos quippe militabimus barbaros qui nos iampridem re, nunc vero spoliare pergunt etiam libertate. Igitur eamus ducere in servitium Persas; hi quibus turpe erat servientibus non subvenire, enim nunc iam etiam ipsi servimus» Et haec quidem dicta praesentibus. Edicit tamen eadem illa sententia et per singula oppida civitatesque ut una cum classibus hi qui armorum desiderio tenerentur ad sese confluerent.
}

8. Pero lo más interesante es que este episodio de la reunión de los griegos tras la muerte de Filipo, ante los que Alejandro pronuncia una arenga decisiva, está muy bien documentado en la amplia y dispersa tradición medieval, que mezcla lo histórico y lo novelesco, sobre la vida y obras del rey macedonio. Textos en los que, además, la asamblea desarrollada en Pela es adaptada al contexto medieval, transformándola en unas "cortes». Entre estos testimonios de época medieval que lo ilustran, son destacables dos.

El primero lo encontramos en la Historia de Preliis Alexandri Magni, obra latina del siglo X escrita por el arcipreste León de Nápoles a partir de un manuscrito hoy perdido del Pseudo-Calístenes ${ }^{36}$. Esta Historia, en sus varias recensiones, tuvo una gran difusión en la Edad Media, acabando por sustituir en el favor de los lectores a obras como el epítome de Julio Valerio. Pero, en lo que a nosotros nos interesa, hemos de destacar que se llevó a cabo una traducción de esta obra (en su recensión J2) al castellano en el escriptorio alfonsí. Esta versión en castellano forma parte de la Cuarta Parte de la Historia General de Alfonso X el Sabio, lo que nos ofrece un pasaje que hay que situar en el mismo contexto creativo en el que se compuso la Estoria de España ${ }^{37}$ :

34. Cf. la amplia introducción de García Gual (1977).

35. Seguimos el texto editado por Rosellini (2004). El texto de Julio Valerio circuló en la Edad Media sobre todo en su forma abreviada (el denominado Iuli Valerii Epitome editado por Zacher en 1867).

36. Cf. Cary (1956: 38 ss.). Cf. la introducción de Krantz (1991: ix-xxxvii) sobre el texto latino, sus recensiones y su enorme influencia durante este período.

37. Cf. González Rolán y Saquero (eds.) (1982: 73-4). 
XII De cómo ayuntó el rey Alexandre a sus pueblos después de la muerte de Filipo

Muerto el rey Philippo, ayuntó el rey Alexandre los ricos omnes del regno de Macedonia e sus pueblos, e fizo sus cortes con ellos, e el día que lo començó, assentósse por princep e señor en la siella del rey Philippo, so padre, en su palacio, e dixo assí a todos: «Varones de Macedonia, los tracianos e los tessalos e los griegos e los otros d'otras tierras que aquí estades, catad e veed a Alexandre, e tened los ojos e los corazones en él. Vos sabedes cómo fata el día d’oy fuestes pecheros de los bárbaros de Perssia, más conórto-vos yo agora e esfuérço-vos e dígo-vos que nos ayades d'ellos ningún miedo, e el pavor fata oy que de los bárbaros oviestes que'l parpadees de vos d'aquí adelant...»

En este caso, un Alejandro con claros ropajes medievales aparece representado convocando unas «cortes» (hay que destacar que se emplea la misma frase que hemos visto en el episodio de las Navas de la historia alfonsí: «ayuntó el rey Alexandre los ricos omnes del regno ... e fizo sus cortes con ellos») en las que reúne a unos contingentes de hombres que divide en tres grupos («varones de Macedonia», "tracianos y tessalos e los griegos» y «los d'otras tierras») a los que exhorta a luchar contra el enemigo común, los persas, antes de emprender la expedición a Asia. Una exhortación que recibe la respuesta favorable de un auditorio entregado.

El segundo testimonio es el episodio de la reunión de los griegos antes de la expedición de conquista asiática que encontramos en el Libro de Alexandre (c. 199-210). Una obra fechada en diferentes momentos del siglo XIII que tuvo una especial trascendencia en la corte castellana (se duda entre Fernando III y Alfonso X como receptores de la obra) por su carácter de speculum principis y por su enfoque enciclopédico ${ }^{38}$. En este contexto, hemos de destacar un pasaje en el que el poeta se detiene a describir de manera muy detallada cómo Alejandro, por medio de unos "pregones», mandó reunir a todos los hombres de su reino (ya fuesen peones o caballeros) para una reunión o «cortes» en las que el macedonio les dirige un discurso exhortativo (en este caso definido como un «sermón») con el que les conmina a acabar con el poderío de los persas ${ }^{39}$ :

\begin{tabular}{|c|c|}
\hline $\begin{array}{l}\text { Fueron por tod'el regno } \\
\text { los unos con menazas, } \\
\text { que a cab de tres meses } \\
\text { peones, cavalleros, }\end{array}$ & $\begin{array}{l}\text { los pregones echados, } \\
\text { los otros con falagos, } \\
\text { fuessen todos llegados, } \\
\text { todos bien aguisados. }\end{array}$ \\
\hline $\begin{array}{l}\text { Cuand' oyeron las gent } \\
\text { esperar nos quisieron } \\
\text { venián los cavalleros, } \\
\text {-en Roma más apriesa }\end{array}$ & $\begin{array}{l}\text { tes tan cuitados pregones } \\
\text { merinos nin sayones; } \\
\text { sí fazién los peones, } \\
\text { non van a los perdones-. }\end{array}$ \\
\hline $\begin{array}{l}\text { La corte fue llegada } \\
\text { semejava que todos } \\
\text { cuando los vió el rey, } \\
\text { quisquier ge lo verié }\end{array}$ & $\begin{array}{l}\text { como el rey mandara, } \\
\text { venién a fust'o a vara; } \\
\text { alegrósle la cara, } \\
\text { que la tenié más clara. }\end{array}$ \\
\hline
\end{tabular}

38. Cf. Arizaleta (2000: 5): «es una enciclopedia en romance y en versos que reúne fragmentos de antología de diferentes fuentes».

39. Cf. Cañas (1983: 121-122). 
Sedién çerca del rey todos los ançïanos, los de las barvas sarras, de los cabellos canos; estavan más alexos los niños más livianos, los de media edat pusieron los medianos.

Los pueblos eran muchos, grandes las peonadas; non les cabién los campos, sedién más alongadas; tanto eran las órdenes a razón assentadas como si fuessen siempre en aquello criadas...

El rey sedié en medio a cada part catando, cuanto más los catava, más se iba pagando; todos oreja escucha estaban esperando qué fablariá el rey que estaba callando.

Cuando él vió su ora, empeçó su sermón: «Oitme, fijosdalgo, un poco de razón; hevos yo de gradir mucho toda sazón porque obedeçistes tan bien el mi pregón.

Sabedes vuestros padres en cuál vida finaron, ellos a su avuelos en tal se los fallaron; en grant premia bivieron, nunca dent se quitaron, cual ellos la ovieron a nos tal la lexaron.

Avián al rey de Persia por debdo a servir, quanto él les mandava aviénlo a complir, aviénse cada año todos a redemir; del mal sabor que he non lo puedo dezir.

Los nietos non podemos dessa rede exir, si do ellos bivieron queremos nos bevir; mas si esto quisierdes una vez aborrir, faré venir a Dario merçed a vos pedir.»

Y hay que destacar que esta arenga de Alejandro, a la que los medievalistas ha definido como "sermón ante las Cortes de Grecia» con el que exhorta a luchar contra el persa ${ }^{40}$, recibe la respuesta unánime del conjunto de los vasallos que forman parte de este auditorio, que el propio poeta define como «senado» (c. 210), y que prometen seguirle hasta la muerte:

Calló el rey con tanto, respuso el senado:

«Señor, nos presto somos por complir lo mandado

do tú nunca quisierdes iremos nos de grado,

e pornemos los cuerpos e quant' emos ganado»

Si tenemos en cuenta este episodio, tal y como hemos comprobado que aparece en la tradición medieval castellana de Alejandro vigente en el siglo XIII, y lo comparamos con la reunión de aliados que celebra Alfonso VIII en Toledo

40. Cf. Grande (2008: 478 y 487). 
antes de la Batalla de las Navas de Tolosa, las palabras exhortativas que les dirige y la respuesta que recibe (todos los asistentes responden con una sola voz), nos encontramos ante un paralelo bien conocido en aquellos ańos que, en origen, creemos que fue buscado de manera intencionada por Jiménez de Rada en su historia. Un paralelo que en el caso del arzobispo se limitó a la elaboración de la escena de las "cortes» en sí misma sin inclusión de discursos. Desde el punto de vista de la mentalidad medieval castellana, se producía una clara asimilación entre una escena y otra: en ambos casos estamos ante unas convocatorias de tropas que suponen el comienzo de una campańa decisiva contra un enemigo infiel y que anteceden a una lucha que cambiará para siempre el curso de la historia. En un caso, la del conjunto de los macedonios, griegos y mercenarios al mando de Alejandro; en el otro, el de los cristianos (castellanos, espańoles y ultramontanos) al mando de Alfonso VIII.

9. Es posible que fuese un relato que siguiese fielmente la exposición de Jiménez de Rada lo que pudo haberse plasmado inicialmente en el esbozo de la parte de la Estoria de España de Alfonso X en la que se relataban los hechos previos a las Navas. Sin embargo, en la reelaboración posterior que se llevó a cabo entre finales del siglo XIII y principios del XIV y que generó el texto que hoy conocemos, los nuevos redactores no se contentaron con la simple traducción del original latino. Decidieron aprovechar las posibilidades retóricas que ofrecía este episodio e introdujeron como una clara interpolación tres arengas que no estaban en las fuentes originales. Desde nuestra perspectiva, no se trata de arengas inventadas o del recuerdo lejano de alguno de los testigos originales que acabó tomando forma en este pasaje ${ }^{41}$, sino que creemos que los interpoladores están reutilizando, con la intención de introducir discursos en estilo directo, el contexto retórico que proporcionaba el relato de Jiménez de Rada. Un texto en el que se hablaba de la reunión en Toledo de un ejército cristiano formado por «una muchedumbre tan abigarrada, tan distinta, tan opuesta $»^{42}$. Se trataría, además, de unas arengas que permitían incidir en el referente alejandrino de las "Cortes» previas a la expedición de Asia, que era patente en la obra del arzobispo toledano. Un referente en el que, como hemos visto en otros testimonios castellanos contemporáneos, se insertaba una arenga del rey macedonio dirigida a diferentes pueblos griegos («Varones de Macedonia, los tracianos e los tessalos e los griegos e los otros d'otras tierras que aquí estades...» $)^{43}$. De hecho, hay que destacar que en el texto alfonsí también se habla en similares términos de que el rey Alfonso convocó unas «cortes» (cap. 1013: «fizo partes destas yentes, et ayunto luego en la primera los fijosdalgo et los otros omnes de armas sus naturales, et fizo sus cortes con ellos et dixoles...»), ante las que se pronuncia la primera parte de esta larga arenga.

41. Cf. Alvira Cabrer (2012: 211): «Es posible que ... estemos ante un recuerdo lejano, más o menos fiel, de un hecho real, pero la falta de datos impide sostener la historicidad que pretende el autor de la Estoria de España».

42. Cf. Libro VIII, cap. IIII.

43. Cf. González Rolán y Saquero (eds.) (1982: 73-4). 
Las otras dos partes que siguen han de cambiar de contexto por fuerza, ya que el interpolador no podía hacer que los otros hispanos o los ultramontanos estuvieran presentes en unas «cortes» a las que sólo podían acudir los castellanos.

Con todo, lo más llamativo del caso de la Estoria de España alfonsí es que no se trata de tres arengas cualesquiera sin conexión entre sí, sino que en conjunto conforman una estructura retórica claramente deudora de un modelo clásico de discurso exhortativo que fue ampliamente utilizado en la historiografía antigua: el modelo de la epipólesis o revista de tropas. Un tipo de discurso de raigambre homérica que, retomado por historiadores clásicos como Tucídides y Jenofonte, tuvo una especial fortuna a la hora de representar a Alejandro Magno arengando antes de batallas clave como Iso y Gaugamela. Un proceder que se puede observar en autores tan diferentes de la vulgata alejandrina como Pompeyo Trogo (epitomizado por Justino), Arriano o Quinto Curcio ${ }^{44}$. Un tipo de discurso que, sin embargo, y de manera muy significativa, no encontramos en muchas de las obras medievales dedicadas a relatar las hazañas del monarca macedonio y que se corresponden con el contexto literario del siglo XIII contemporáneo con la obra de Jiménez de Rada. De hecho, en el momento previo a la batalla de Iso, tal y como puede comprobarse en obras como la Historia de Preliis o El libro de Alexandre, sus autores no presentan a Alejandro pronunciado una epipólesis sino sólo una arenga más o menos elaborada que no sigue este esquema retórico ${ }^{45}$. Un proceder medieval que contrasta con el hecho de que éste es precisamente el tipo de discurso que encontramos en autores latinos como Justino o Quinto Curcio en el momento de relatar los momentos previos a este enfrentamiento bélico en Iso, que fue decisivo para la victoria definitiva de los griegos sobre los persas en Asia ${ }^{46}$. Así, lo podemos ver tanto en el caso de Justino (11.9.4-7) como en el de Quinto Curcio (3.10.4-10) ${ }^{47}$, cuyas obras fueron conocidas y difundidas en la Edad Media, aunque será precisamente a partir de finales del XIII y principios del XIV cuando vuelvan a ser tenidas realmente en cuenta y valoradas como más fidedignas que las obras medievales de contenido más novelesco ${ }^{48}$.

44. Cf. Carmona Centeno (2008) y (2014).

45. Cf. González Rolán y Saquero (eds.) (1982: 109) y Cañas (1983: 206-7).

46. Cf. Iglesias-Zoido (2010) para un análisis detallado del componente retórico de estos episodios militares y del papel jugado por los discursos exhortativos.

47. Cf. también el historiador griego Arriano, Anábasis 2.10.2, que presenta el discurso de Alejandro como una epipólesis.

48. Cf. Winterbotton en Reynolds (ed.) (1983: 148-149) y Brunhölzl (1986), sobre los avatares de la transmisión medieval del texto de Curcio. Hay que destacar que la influencia de su obra en la Edad Media apenas ha recibido atención, ya que los estudios no han avanzado demasiado desde la obra clásica de Dosson (1887), quien ya apuntaba la existencia de más de cien manuscritos medievales (pp. 315-356), la mayor parte de ellos de origen francés, entre los que destaca (pp. 365 ss.) el interés por los discursos que se percibe en algunos de ellos. Incluso, hay alocuciones de Curcio en excerpta de discursos historiográficos (Salustio, Livio y Curcio). Sobre los manuscritos de Curcio copiados en los siglos XI y XII, cf. Munk Olsen (1982: 355362). Detalles sobre la importancia del texto de Quinto Curcio para la narrativa medieval de Alejandro durante la baja edad media en Engels (1998: 15-24). 
10. Ambas obras, no obstante, presentan diferencias significativas a la hora de describir este episodio y de reflejar los discursos que se pronunciaron en su desarrollo.

El texto de Justino ${ }^{49}$ en el que se relatan los antecedentes de la batalla de Iso es bastante breve (11.9.1-8) y apenas proporciona información en estilo indirecto sobre la arenga de Alejandro (11.9.4-7) y sobre la réplica que, en el campo enemigo, habría pronunciado el rey persa Darío (11.9.8). No obstante, el epitomizador de Las historias filípicas de Pompeyo Trogo deja constancia de que en este episodio se pronunciaron dos discursos y que el primero fue una epipólesis con la que Alejandro se dirigió a cada pueblo (en este orden: primero Ilirios y tracios; luego a los griegos y finalmente a los macedonios) con palabras distintas para cada uno de sus auditorios (9.9.3): circumvectus suos singulas gentes diversa oratione adloquitur.

El caso de Curcio, por su parte, es sin duda el más llamativo y merece la pena que nos detengamos en un análisis más detallado para poner de manifiesto los puntos de contacto con las arengas pronunciadas por el rey Alfonso VIII. De hecho, el texto conservado de Curcio (el conocido en los manuscritos de la obra que circularon en la Edad Media) comienza justo en este episodio del libro III, siendo ésta la primera gran arenga de Alejandro con la que se encontraban los lectores. El primer dato reseñable es que Curcio no presenta dos discursos contrapuestos (Alejandro/Darío) como hace Justino, sino que ha optado por reproducir solo las palabras del rey macedonio. El segundo dato es que este discurso es una epipólesis. Así, acorde con este tipo de exhortación, el historiador romano ha optado por introducir antes de la batalla de Iso una serie de arengas en estilo indirecto con las que muestra al rey recorriendo las tropas a caballo (obequitaret) y dirigiéndose a sus tropas con diferentes discursos (varia oratione) adaptados a las características de uno de los contingentes a los que se dirige (3.10.4). El tercer dato es que Curcio ha insertado un discurso (3.10.410) que, aunque está en estilo indirecto, ofrece mucha más información sobre las palabras pronunciadas ante cada uno de los contingentes que conformaban el ejército. El cuarto dato, y no el menos importante, es el orden que siguen sus diferentes alocuciones: macedonios, griegos y, finalmente, ilirios y tracios.

En primer lugar, Alejandro exhorta a sus compatriotas macedonios (3.10.47) señalando las futuras riquezas y beneficios que se derivarán de la victoria (3.10.4-6), la debilidad del enemigo (3.10.6) y, finalmente (3.10.7-8), les recuerda el ejemplo de su padre, Filipo, y el de las victorias que se han sucedido desde Grecia hasta llegar a esa parte de Asia.

Cumque agmini obequitaret, varia oratione, ut cuiusque animis aptum erat, milites adloquebatur. Macedones, tot bellorum in Europa victores, ad subigendam Asiam atque ultima Orientis non ipsius magis quam suo ductu profecti, inveteratae virtutis admonebantur: illos terrarum orbis liberatores emensosque olim Herculis et Liberi patris terminos non Persis modo, sed etiam omnibus gentibus iuposituros iugum. Macedonum

49. Cf. Fraker (2006: 89-93) sobre la influencia directa del epítome en la escritura de episodios alfonsíes como el que protagonizan Dido y Eneas en Cartago. 
provincias Bactra et Indos fore. Minima esse, quae nunc intuerentur, sed omnia victoria aperiri. Non in praeruptis petris Illyriorum et Thraciae saxis sterilem laborem fore, spolia totius Orientis offerri. gladio futurum opus: totam aciem suo pavore fluctuantem umbonibus posse propelli. Victor ad haec Atheniensium Philippus pater invocabatur, domitaeque nuper Boeotiae et urbis in ea nobilissimae ad solum dirutae species repraesentabatur animis. Iam Granicum armem, iam tot urbes aut expugnatas aut in fidem acceptas omniaque, quae post tergum erant, strata et pedibus ipsorum subiecta memorabat.

En segundo lugar, el historiador presenta a Alejandro dirigiéndose al conjunto de los griegos (3.10.8-9), a los que recuerda (admonebat, referebat) la excusa oficial de la campaña de Asia: vengar el ataque de los persas contra Grecia en las Guerras Médicas:

Cum adierat Graecos, admonebat ab his gentibus inlata Graeciae bella Darei prius, deinde Xerxis insolentia, aquam ipsos terramque poscentium, ut ne que fontium haustum nec solitos cibos relinquerent deditis. Ab his templa minis et ignibus esse deleta, urbes eorum expugnatas, foedera divini humanique iuris violata referebat.

Y, finalmente, Alejandro se dirige a los pueblos extranjeros y mercenarios que le acompañan, ilirios y tracios (3.10.9-10), a quienes invita, directamente y sin pudor, al pillaje.

Illyrios vero et Thracas rapto vivere adsuetos aciem hostium auro purpuraque fulgentem intueri iubebat, praedam, non arma gestantem: irent et inbellibus feminis aurum viri eriperent, aspera montium suorum inga nudasque calles et perpetuo rigentes gelu divitibus Persarum campis agrisque mutarent.

Tanto en el orden de las intervenciones como en parte del contenido argumentativo de alguna de ellas son perceptibles puntos de contacto con los discursos de Alfonso VIII en el capítulo 1013 de la Estoria de España. El orden de las intervenciones (ajustado a un tipo concreto de epipólesis denominado por la crítica de «descomposición de auditorio y de contenido») $)^{50}$ sigue la aparente disposición física de las tropas en el recorrido a caballo de Alejandro. Sin embargo, hay que destacar que Quinto Curcio ha establecido una clara gradación en la que se destaca la cercanía o alejamiento del general con respecto a los soldados. Por eso comienza por el contingente propio (los macedonios),

50. Cf. la terminología de Longo (1983), retomada y ampliada por Carmona Centeno (2008) y (2014), quienes distinguen cuatro tipos: 1) Epipólesis simple, cuando se expresa que un general arengó a sus hombres a medida que recorría el ejército pero nada se dice de que pronunciara varios discursos ni de que se dirigiera de forma individual a distintos interlocutores. 2) Epipólesis con descomposición, cuando se expresa que un general lanzó varias exhortaciones en su recorrido dirigiéndose de forma particular a distintos interlocutores. Este tipo de epipólesis puede dividirse a su vez en dos subtipos: 2.1) Epipólesis con descomposición del auditorio, cuando se expresa que un general pronunció varias exhortaciones en su recorrido dirigiéndose de forma particular a distintos interlocutores, pero este hecho no se ve materializado en la presentación de esos discursos, sino que solo se ofrece uno que funciona de sumario de todos los pronunciados. 2.2) Epipólesis con descomposición del auditorio y del contenido, cuando se expresa que el general lanzó varias exhortaciones en su recorrido dirigiéndose de forma particular a distintos interlocutores, hecho que se ve materializado en la presentación de dichos discursos. 
sigue por el conjunto de los griegos y acaba con los mercenarios extranjeros. Disposición que se corresponde con el diferente contenido de cada exhortación. Además, por su extensión y argumentación, la sección más significativa es la dirigida a los macedonios. De hecho es la que más se ajusta al modelo clásico de arenga con un amplio recurso a los argumentos principales o capitula finalia: Alejandro muestra los enormes beneficios de la lucha, minimiza las fuerzas del enemigo y, finalmente, recurre a los ejemplos del pasado ${ }^{51}$. Una argumentación en la que pueden encontrarse también paralelos con las arengas de Alfonso VIII, especialmente en el caso de la dirigida al conjunto de los españoles, en la que (como ocurre aquí cuando Alejandro se dirige a los griegos) se destaca sobre todo la idea de la venganza frente al agravio sufrido previamente por parte de un bárbaro (los persas que invadieron Grecia) o infiel (los moros que se apoderaron de la península).

Con todo, estos posibles paralelos argumentativos no son el elemento más importante, ya que, como es lógico, el contenido concreto de cada grupo de arengas se ajusta tanto a las diferentes situaciones bélicas como a las diferentes mentalidades de los contendientes. Por citar sólo un factor, el tema de la cruzada cristiana contra el infiel supone una barrera infranqueable ${ }^{52}$. La clave explicativa de esta interpolación ha de entenderse en un plano formal y retórico: sobre el paradigma retórico que supone este tipo de modelo discursivo que encontramos en Quinto Curcio, nuestra tesis es que los redactores de esta interpolación de la Estoria de España, conscientes del referente alejandrino que ya era perceptible en la crónica que hizo Jiménez de Rada de este episodio decisivo de la cruzada hispana contra los musulmanes, habrían optado por reescribir el episodio poniendo en boca del rey castellano un tipo de discurso especialmente característico del rey macedonio y que, como hemos visto en Curcio, fue decisivo para animar al heterogéneo conjunto de sus tropas antes de la batalla decisiva que determinó la victoria en Asia. Y en esta auténtica amplificatio, más que a la tradición medieval de Alejandro, desarrollada en obras como la Historia de Preliis o El libro de Alexandre, los interpoladores habrían recurrido al referente más estrictamente clásico que proporcionaba una fuente historiográfica latina como Quinto Curcio. Un autor que en este momento del siglo XIV sería considerado como más adecuado desde un punto de vista imitativo. El seguimiento de modelos historiográficos como los que encontramos en autores latinos como Curcio, cuyos discursos además habían recibido atención en los manuscritos medievales como ejemplos de oratoria, se habría llevado a cabo en un contexto literario e historiográfico en el que la introducción de discursos en la historia, en la estela de los modelos clásicos, había cobrado un nuevo auge.

51. Cf. el destallado estudio de Albertus (1908) tanto de la dispositio como de la inventio de la arenga historiográfica grecolatina y los trabajos de Bliese (1989) y (1991) sobre su adaptación medieval.

52. Cf. García Fitz (2008). 
11. Este cambio de mentalidad que llevó a la inclusión de discursos también se observa en otras obras históricas contemporáneas y posteriores. De hecho, la prueba de que la ocasión histórica de la batalla de las Navas pedía a gritos la inserción de discursos exhortativos la encontramos en dos textos castellanos que nos van a permitir contextualizar aún más la labor retórica realizada en la Estoria alfonsí. Uno de ellos, el más breve, posiblemente fue redactado en los mismos años en los que se reescribió la Estoria de España. El otro, mucho más desarrollado, es el fruto de un contexto plenamente humanístico y ofrece un paralelo posterior muy significativo.

El primer pasaje es otro ejemplo de amplificatio retórica que encontramos en una de las traducciones castellanas de la Historia de rebus Hispaniae de Jiménez de Rada que se llevaron a cabo en el último tercio del siglo XIII ${ }^{53}$. Nos referimos a la Estoria de los Godos, obra en la que el escueto diálogo en mitad de la batalla de las Navas entre el rey Alfonso y el arzobispo que nos ofrecía el propio Jiménez de Rada ${ }^{54}$ fue enriquecido con dos breves exhortaciones del monarca dirigidas a los castellanos y a los españoles:

El rey don Alfonso quebro su coraçon et lorando por los oios dixo: «Castellanos, hoy es vuestro día; ¡catad la de Alarcos!». Pues dixo: «Aragoneses et navarros: ¡catad quales fuestes sienpre, que hoy es vuestro dia! $!^{55}$

El editor del texto, a la hora de explicar la inserción de estas palabras en estilo directo, considera que puede ser fruto de una «novelización» debida al deseo de mantener la tensión dramática de la narración ${ }^{56}$. Para nosotros, este texto es una prueba de que el autor de la Estoria claramente veía la necesidad de representar al rey arengando a sus tropas en una ocasión tan trascendental como la de las Navas, lo que le llevó a insertar estas breves exhortaciones dirigidas a castellanos (a los que recuerda la posibilidad de vengar la derrota de Alarcos) y a aragoneses y navarros (a los que exhorta a actuar de acuerdo con la historia que les precede) para completar el texto de Jiménez de Rada.

El segundo pasaje, con un contenido retórico más significativo, nos lo proporciona un humanista castellano de mediados del siglo XV. Y, desde nuestro punto de vista, ofrece una prueba de que los discursos del capítulo 1013 de la Estoria de España están inspirados en modelos tomados de la historiografía clásica. De hecho, así es como lo interpreta Rodrigo Sánchez de Arévalo en su Compendiosa Historia Hispánica cuando hacia 1470 reescribe el episodio de las $\mathrm{Navas}^{57}$. Esta obra es de enorme valor porque pone de manifiesto la perspectiva con la que un humanista enjuiciaba tanto los hechos como las palabras relacionadas con un episodio de la trascendencia de la batalla de las

53. Sobre la fechación de esta obra en la segunda parte del siglo XIII cf. Jerez (2003).

54. Cf. Libro VIII, cap. X: «Arzobispo, muramos aquí. Pues no es deshonra una muerte tal en tales circunstancias» (Fernández Valverde 1989: 322).

55. Seguimos el texto editado por Ward (2006: 172).

56. Cf. Ward (2006: 192). Sobre otras breves intervenciones en mitad de la batalla atribuidas al rey Alfonso VIII en otras crónicas cf. Alvira Cabrer (2012: 210-212).

57. Sobre Sánchez de Arévalo, cf. Trame (1958) y Tate (1970). 
Navas. Así, en el capítulo XXXV de la tercera parte de esta historia, que lleva por título De gloriosa victoria Alfonsi VIII. contra Sarracenis in illo famoso bello de Navibus Tholose..., el humanista hace un repaso de los puntos esenciales del relato a partir de lo que cuenta la Estoria de España alfonsí, estableciendo una comparación directa entre los hechos allí sucedidos y diversos episodios de la historia clásica ${ }^{58}$. Para los ojos de este humanista de mediados del cuatrocientos son evidentes las similitudes entre la situación vivida por el Rey Alfonso VIII en la batalla de las Navas y la que experimentaron otros protagonistas famosos de la Antigüedad como César o Alejandro, de quien destaca muy especialmente las diferentes ocasiones en las que venció a Darío a pesar de encontrarse en inferioridad numérica ${ }^{59}$. Pero, sobre todo, Sánchez de Arévalo establece una directa comparación entre las palabras de ánimo que podría haber pronunciado el rey castellano y otras arengas clásicas en las que se argumenta contra las desventajas de la inferioridad numérica: la pronunciada por Catilina en la obra del mismo nombre escrita por Salustio (BC 58) y la pronunciada por Alejandro Magno tal y como, según afirma Sánchez de Arévalo, lo relata el historiador romano Quinto Curcio:

Así pues, cuando llegó el día del combate, con el ejército reunido y en formación de batalla, los sarracenos, confiados en su número, gritaban a grandes voces -como es su costumbre- y permanecían impasibles ante el estrépito de sus gritos y sus trompetas, para dar temor a los nuestros y valor a los suyos. Al ver Alfonso a los suyos amilanarse ante la pujanza de los enemigos, les recordó lo que Salustio dice en su Catilinaria: «En un combate el mayor peligro lo corren siempre los más temerosos. A nosotros, soldados de Cristo, el valor nos servirá de muralla, la esperanza de amparo, la gloria de victoria, la justicia de convicción en la victoria». Y añadió: "Que no os asuste el griterío de los enemigos: quienes hablan mucho por su boca guardan el miedo en su corazón». Imitaba Alfonso las palabras de Alejandro Magno, quien, según refiere Quinto Curcio, justo antes de enfrentarse a Darío, en una situación similar se dirigió a sus atemorizadas tropas de esta manera: «¿Por qué os espantáis ante el griterío de estos bárbaros, que es testimonio de su temor y no una prueba de su arrojo? Pues los perros más desventurados tienen por costumbre ladrar más cuanto más les fallan las fuerzas». Cuando terminó de hablar, fortalecidos todos en el Señor se lanzaron contra los sarracenos ${ }^{60}$.

58. Seguimos la edición de Roma de 1470 con actualización de la ortografía, cf. Sánchez de Arévalo (1470: 83r-85r).

59. Cf. Sánchez de Arévalo (1470: 84v).

60. Traducción de J. Villalba Álvarez. Cf. Sánchez de Arévalo (1470: 83v): Adueniente igitur die belli, congregato et instructo exercitu, Sarraceni in multitudine confidentes, ut moris habent, clamitabant magnis vocibus, et diversis sonorum et tubarum strepitibus rigebant: ut nostris timorem: suis vero animum darent. Cum vero Alfonsus suos hostium potentiam formidare conspiceret: ad eos ait quod Salustius in Cathelinario refert. Semper (inquit) in praelio illis est maximum periculum qui maxime timent. Nobis ergo, o Christi milites, audacia pro muro, spes pro securitate, gloria pro victoria, iustitia pro certitudine vincendi habeatur. Et subdit: Nec vos conturbent hi hostium clamores: illis eius pavor est in animo, quibus effussa vox est in ore. Imitatus est Alfonsus Magnum Alexandrum, qui, ut Quintus Curtius refert, contra Darium pugnaturus in simili casu ad suos formidantes ait: Quid Barbarorum clamoribus turbamini, qui timores habent testimonium, non confidentie probationem. Namque canibus infelicioribus mos est quanto plus defecerint vires, eo magis latratibus indulgere. Expletis igitur his verbis, omnes in Domino confortati Sarracenos impetunt. 
Sánchez de Arévalo pone en boca del rey castellano una arenga que está construida a partir de dos citas casi literales de discursos historiográficos. E incluso llega a afirmar que el rey Alfonso imitaba las palabras de Alejandro «según refiere Quinto Curcio» (ut Quintus Curtius refert), quien justo antes de enfrentarse a Darío en una situación similar se dirigió a sus atemorizadas tropas para inspirarles confianza, comparando el griterío de los enemigos con el de los perros que ladran más cuanto más les fallan las fuerzas. Un pasaje que, en realidad, no pertenece a la obra de Curcio, sino a la traducción de Julio Valerio (1.43) de las gestas de Alejandro. Nada extraño por otra parte, ya que este texto, durante el Renacimiento, solía difundirse junto a la historia de Quinto para completar la parte inicial perdida, por lo que la referencia a "Quinto Curcio» debería interpretarse como una alusión a la obra en su conjunto.

Como puede comprobarse, Sánchez de Arévalo sólo entiende el episodio de la Navas en clave de la historiografía clásica y ha recreado las palabras que pudo haber pronunciado el rey Alfonso VIII antes de las Navas de un modo que puede compararse con lo que hicieron los interpoladores de la Estoria de España. En ambos casos se observa el uso retórico de modelos de discursos tomados de la historiografía clásica. Las diferencias se centran en el momento escogido para introducir los discursos y, por lo tanto, en su contenido concreto. Los interpoladores alfonsíes, al seguir fielmente el texto de Jiménez de Rada, optaron por introducir las arengas en el "episodio de las Cortes», donde la presencia de tres grupos de contendientes (castellanos, españoles y ultramontanos) les aconsejó el seguimiento del modelo de la epipólesis, tal y como se encuentra en la historia de Quinto Curcio en la que Alejandro se dirigió a macedonios, griegos e ilirios. Sánchez de Arévalo, por su parte, buen conocedor de Salustio y profundamente influido por sus lecturas de la historiografía clásica, ha optado por presentar al rey castellano como un general grecorromano, arengando a sus hombres justo antes del combate decisivo y poniendo en su boca argumentos que parafrasean dos pasajes muy conocidos de la historiografía antigua en los que se argumenta contra las desventajas de la inferioridad numérica. Un proceder netamente humanístico que ya es fruto de un nuevo tiempo en el que las contiones van a triunfar como modelos oratorios. De hecho, las obras históricas de las siguientes centurias no dejaron de aprovechar esta ocasión y, al relatar lo sucedido en esta batalla, dieron el paso retórico definitivo y no dudaron en presentar incluso dos discursos contrapuestos ante las huestes: los pronunciados por el rey Alfonso y por el rey Moro ${ }^{61}$.

12. En conclusión, en el capítulo 1013 de la Estoria de España alfonsí estaríamos ante un pasaje en el que se pueden percibir dos niveles de influencia clásica que se corresponden con dos épocas y dos modos diferentes de entender

61. Cf. el proceder del padre Mariana (1601: 743-744): «Exhortaron los unos y los otros, y animauan los suyos a la pelea. Los obispos andauan de compañía en compañía, y con la esperança de ganar la indulgencia animauan a los nuestros. El rey don Alonso, desde un lugar algo, para que le pudiessen oyr, dixo en sustancia estas razones ...». «El Moro al contrario, aviso a lo suyos, y les dixo ...". 
el referente que ofrecía la tradición grecolatina. Un primer nivel, que seguía fielmente la narración original de Jiménez de Rada, y que tenía como objetivo comparar las cortes realizadas por Alfonso VIII antes de la batalla de las Navas con las que la tradición medieval muestra qué hizo Alejandro antes de emprender la conquista de Asia. Un segundo nivel, que supone un nuevo modo de concebir el influjo clásico, en el que los redactores de la interpolación del texto alfonsí intentaron años más tarde profundizar en las similitudes perceptibles entre ambos reyes por medio de la introducción de unos discursos en forma de epipólesis o «revista de tropas». Un proceder que era más respetuoso con la tradición historiográfica latina que relataba los hechos del rey macedonio, tal y como aparece personificada en este caso en la obra de Quinto Curcio. Se observa así la influencia coordinada de dos tipos de textos relacionados con la historia de Alejandro que obedecen, a su vez, a dos concepciones historiográficas diferentes. Los redactores de la interpolación de las arengas de Alfonso VIII no solo lograban equiparar ambas acciones (las «cortes» previas a la batalla decisiva) sino también ambos actos discursivos (unas arengas que adoptan la forma de la revista de tropas). Y, de paso, introducían una alusión erudita que podría ser degustada por los conocedores del texto latino de Quinto Curcio.

\section{Bibliografía}

Albertus J. (1908), Die parakletikoi in der griechischen und römischen Literatur, Estrasburgo, K. J. Trübner.

Alvira Cabrer M. (2000), Guerra e ideología en la España Medieval: Cultura y actitudes históricas ante el giro de principios del siglo XIII. Batallas de las Navas de Tolosa (1212) $y$ Muret (1213), tesis doctoral, Madrid, Universidad Complutense.

- (2010), Pedro el Católico, Rey de Aragón y Conde de Barcelona (1196-1213). Documentos, testimonios y memoria histórica, vol. IV, Zaragoza, Institución Fernando el Católico.

- (2012), Las Navas de Tolosa 2012. Idea, liturgia y memoria de la batalla, Madrid, Sílex.

Arizaleta A. (2000), «Alexandre en su Libro», La Corónica, 28: 3-20.

- (2003), «Ut lector agnosceret. discurso y recepción en la obra de Rodrigo Jiménez de Rada (primera mitad del siglo XIII)», Cahiers de Linguistique et de Civilisation Hispaniques Médiévales 26: 163-186.

- (2005), "Las estorias de Alexandre: Rodrigo Jiménez de Rada, historiador de Alejandro Magno (primera mitad del siglo XIII)», en C. Parrilla y A. Chas (eds.), Actas del IX Congreso Internacional de la Asociación Hispánica de Literatura Medieval, La Coruña, Universidad de Coruña, pp. 343-359.

Bautista F. (2006), La Estoria de España en época de Sancho IV: sobre los reyes de Asturias, Londres, University of London.

Bliese J. R. E. (1989), «Rhetoric and Morale: A Study of Battle Orations from the Central Middle Ages», Journal of Medieval History 15: 201-225. 
- (1991), «When Knighly Courage may fail: Battle Orations in Medieval Europe», The Historian 53: 489-504.

Brunhölzl F. (1986), «Curtius Rufus im Mittelalter», Lexikon des Mittelalters, vol. 3, col. 393.

Cañas J. (ed.) (1983), Libro de Alexandre, Madrid, Editora Nacional.

Carmona Centeno D. (2008), La epipólesis en la historiografía grecolatina, tesis doctoral, Cáceres: Universidad de Extremadura.

- (2014), La escena típica de la epipólesis: de la épica a la historiografía, Seminari Romani di Cultura Classica, Roma, Edizioni Quasar (en prensa).

Cary G. (1956), The medieval Alexander, Cambridge, University Press.

Catalán D. (1963), «El taller historiográfico alfonsí. Métodos y problemas en el trabajo compilatorio", Romania 84: 354-375.

- (1997), De la silva textual al taller historiográfico alfonsí. Códices, crónicas, versiones y cuadernos de trabajo, (Fuentes cronísticas de la Historia de España, IX) Madrid, Fundación Ramón Menéndez Pidal-Universidad Autónoma de Madrid.

Dosson S. (1887), Étude sur Quinte Curce. Sa vie et sa œuvre, París, Hachette.

Engels L. J. (1998), «Alexander the Great», en W. P. Gerritsen y A. G. van Melle (eds.), A Dictionary of Medieval Heroes: Characters in Medieval Narrative Traditions, trad. Ing., Woodbrigde, The Boydell Press, pp. 15-24.

Falque E. (ed.) (2003), Lucas Tudensi Chronicon Mundi (CCCM 74), Turnholt: Brepols. Fernández Ordóńez I. (1988), «La Estoria de España, la General Estoria y los diferentes criterios compilatorios", Revista de Literatura 50:15-35.

- (1992), Las Estorias de Alfonso el Sabio, Madrid, Istmo.

- (2002-2003), «De la historiografía fernandina a la alfonsí», Alcanate 3: 93-133.

Fernández Ordóñez I. (ed.) (2000), Alfonso X el Sabio y las Crónicas de España, Valladolid, Fundación Santander Central Hispano.

Fernández Valverde J. (ed.) (1987), Roderici Ximenii de Rada Historia de rebus Hispanie, sive, Historia Gothica, (CCCM 72), Turnholt, Brepols.

- (trad.) (1989), Rodrigo Jiménez de Rada: Historia de los hechos de España, Madrid, Alianza Editorial.

Fraker Ch. (2006), "The rhetoric in the Estoria de España of Alfonso X el Sabio», Talia dixit 1, 81-104.

García Fitz, F. (2005), Las Navas de Tolosa, Barcelona, Ariel.

- (2008), «La arenga militar en la historiografía de las Cruzadas: la ideología patente», en J. C. Iglesias Zoido (ed.), Retórica e historiografía. El discurso militar en la historiografia desde la Antigüedad hasta el Renacimiento, Madrid, Ediciones Clásicas, pp. 429-466.

- (2012), Las Navas de Tolosa (Edición del VIII Centenario), Barcelona, Ariel.

García Gual, C. (1977), Vida y hazañas de Alejandro de Macedonia, Madrid, Gredos.

Gaullier-Bougassas, C. (ed.) (2011), L'historiographie médiévale d'Alexandre le Grand, Turnholt, Brepols.

González Rolán, T. y Saquero, P. (eds.) (1982), La historia novelada de Alejandro Magno. Edición acompañada del original latino de la Historia de Preliis (Recensión J2), Madrid, Universidad Complutense. 
González Rolán T., Saquero P., López Fonseca A. (eds.) (2002), La tradición clásica en España (siglos XIII-XV). Bases conceptuales y bibliográficas, Madrid, Ediciones Clásicas.

Grande Quejigo F. J. (2008), "Los discursos en el Libro de Alexandre: política y retórica ante la guerra", en J. C. Iglesias Zoido (ed.), (ed.), Retórica e historiografía. El discurso militar en la historiografía desde la Antigüedad hasta el Renacimiento, Madrid, Ediciones Clásicas, pp. 429-466.467-488.

Iglesias Zoido J.C. (2010), "The Pre-Battle Speeches of Alexander at Issus and Gaugamela", Greek, Roman and Byzantine Studies 50, 215-241.

Iglesias Zoido J. C. (ed.) (2008), Retórica e historiografía: el discurso militar en la historiografía desde la Antigüedad hasta el Renacimiento, Madrid, Ediciones Clásicas.

Jerez E. (2003), «La Historia gothica del Toledano y la historiografía romance», Cahiers de linguistique et de civilisation hispaniques médiévales 26: 223-239.

Krantz D. M. (1991), The Romances of Alexander, New York, Garland.

Linehan P. (1993), History and the Historians of Medieval Spain, Oxford, Clarendon Press.

- (2000), «Lucas de Tuy, Rodrigo Jiménez de Rada y las historias alfonsíes», en Fernández Ordóñez (ed.) (2000:19-36).

Longo O. (1983), "I discorsi tucididei: uditorio indiviso e scomposizione d'uditorio", Museum Criticum 8, 139-159.

Mariana J. De (1601), Historia general de España. Compuesta primero en latin, despues buelta en castellano por Juan de Mariana, doctor theologo, de la Compañia de Jesus, vol. I, Madrid, Imprenta de Pedro Rodríguez.

Martin G. (1991), "Cinq opérations fondamentales de la compilation. L'exemple de l'Histoire d'Espagne (étude segmentaire)", en L'historiographie médiévale en Europe, Paris, CNRS, pp. 99-109.

Menéndez Pidal R. (ed.), Primera Crónica General de España, editada por R. Menéndez Pidal con un estudio actualizador de Diego Catalán (tercera reimpresión), 2 vols., Madrid, Gredos.

Munk Olsen B. (1982), L'étude des auteurs classiques latins aux XI et XII siècles (Documents, Études et Répertoires), vol. I, París, Institut de Recherche et d'Histoire des Textes.

Reynolds L. D. (ed.) (1983), Texts and Transmission: A Survey of the Latin Classics, Oxford, University Press.

Rodríguez A. (2003), "De rebus Hispaniae frente a la Crónica latina de los reyes de Castilla : virtudes regias y reciprocidad política en Castilla y León en la primera mitad del siglo XIII", Cahiers de Linguistique et de Civilisation Hispaniques Médiévales 26: 133-149.

Rodríguez Velasco J. D. (1993-1994), «De oficio a estado: la caballería entre el Espéculo y Las Siete Partidas", Cahiers de Linguistique Mediévale 18-19: 49-77.

Rosellini M. (2004), Iuli Valeri Res Gestae Alexandri Macedonis translatae ex Aesopo Graeco, Múnich y Leipzig.

Sánchez de Arévalo R. (1470), Compendiosa historia hispanica, Roma, Udalrico Gallo. Tate R. B. (1970), Ensayos sobre la historiografía peninsular del siglo XV, Madrid, Gredos. 
Trame R. H. (1958), Rodrigo Sánchez de Arévalo 1404-1470. Spanish Diplomat and Champion of the Papacy, Washington, The Catholic University of America.

Ward A. (ed.) (2006), Estoria de los Godos. Critical edition and introduction, Oxford, Society for the Study of Medieval Languages and Literature.

Winterbotton M. (1983), "Curtius Rufus», en Reynolds (ed.) (1983: 148-149).

Zuwiyya D. (ed.) (2011), A Companion to Alexander Literature in the Middle Ages, Leiden, Brill. 